\title{
Use Areas of Nanotechnology in Veterinary Medicine
}

\author{
Ali Bilgili $^{1}$ and M. Haydar Uysal $^{2}$ \\ 1. Department of Pharmacology and Toxicology, Faculty of Veterinary Medicine, Ankara University, Ankara 06110, Turkey \\ 2. Department of Pharmacology and Toxicology, Health Sciences Institute, Ankara University, Ankara 06110, Turkey
}

\begin{abstract}
Nanotechnology is briefly a science field searching substances having superior properties at nano-scale (different optical, mechanical and thermal properties) and those to be potentially produced in the future from these substances. Accordingly, it is a technology regarding opportunities providing the development during the formation of new products not applicable in advance and the formation of new processes. This technology that has the potential of affecting the world economy is at the development stage just now and it is thought that it will cause high changes in human life in the future 15-20 years. Nanotechnology provides an opportunity bringing new technological developments and applications appeared as impossible before as well as bringing a new perspective for available technological processes. In the context of the report in the light of mentioned information, brief information was given on the place and use of nanotechnology in fields such as systems of drug delivery, diagnosis of diseases, vaccine development, treatment of diseases, improvement of fertility functions of animals, determination of fertility capabilities of animals, store of gametes and embryos by freezing, animal breeding, farm medicine, meat and meat production, food safety, and neutralization of animals as use areas in veterinary medicine. Furthermore, in our country and the world, knowledge regarding the intended use of nano-technology based drugs used in veterinary medicine was presented in Table 1.
\end{abstract}

Key words: Nanotechnology, veterinary medicine, nanomedicine.

\section{Introduction}

Nanotechnology is a scientific area that searches the materials with high features in nano-scale (different optic, mechanic and thermal features) and the materials that have producible potential in the future in these materials [1]. According to nanometer scale, the materials having scales at 1-100 $\mathrm{nm}$ are termed as nanomaterial. When controlled after the materials are used as atomic, molecular and multi-molecular, they are reported to acquire high feature and performance [2]. In the twentieth century, one of the most important physicists, Richard Feynman, made a first speech about nano-materials in 1959, with the title "There's Plenty of Room at the Bottom" by emphasizing the nanotechnology importance.

Feynman implies that nanotechnology has an unimaginable mystery with a sentence "Why do we write the Britannica encyclopedia of 24 volumes in the

Corresponding author: Ali Bilgili, PhD, professor, research fields: pharmacology, toxicology, nanotechnology. pinhead?" in his speech, he lays the foundation of nano-science and nanotechnology.

Norio Taniguchi is a person who first used "Nanotechnology" term in 1974. Nanoscience and nanotechnology is a science including the different occupations and is a technological area [3]. Scientists related to material science, mathematics, physics, chemistry, biology, pharmaceutics, veterinary medicine, medicine, computer, electronics sciences carry out studies having a promising future for society with research and development on nanotechnology [4].

\section{Important Features of Nanotechnology}

- Nanotechnology is a technology of opportunities with the development of new materials related to non-viability materials in advance and the generation of new processes.

- Nanotechnology is appeared to be preferred to the traditional technologies with its use in new production processes and in obtaining the product of 
high standards.

- Nanotechnology is a technology putting forward that more than one scientific field studies together. It consists of various technological and scientific disciplines such as the nanostructured materials, nano-electronics, nano-biotechnology, nano-analytics.

- Nanotechnology is universal but does not belong to any person or institution. Nanotechnology that has potential to affect the world economy is yet in the development stage. It is thought that nanotechnology will lead to huge changes in human life in the next 15-20 years. Nanotechnology gives both new point of view to the current technological methods and provides an opportunity to the new technologies and practices appeared like impossible before [5].

\subsection{Nanotechnology in Drug Delivery Systems}

Area to be most benefited from nanotechnology in veterinary medicine is pharmacological sciences. These structures have both preventive effects against viral or bacterial diseases and benefits of accelerating of wound healing and attenuating of pain. In addition, these new compounds can carry drug and genes to the target site. These systems have important effects on absorption, distribution, and excretion rate of drugs or other substances in the body. Thus, they provide the control chance for the pharmacodynamics and pharmacokinetics of drug [6]. In animals, in smart drug delivery systems, small and closed drug packets are used in that drug is achieved to the target site and the necessary drug is carried. Smart drug delivery systems allow antibiotic use in amounts less than possible. In these small packets, "address tag" coded as molecular facilitates the delivery of packets on the correct site in the body. Mechanical systems with nano- and micro-scale function as "carriers" in the smart drug delivery systems. Smart delivery systems can perform processes such as the ability of it to decide the regulation in the process of delivery of drug or the ability of it to make the drug adding according to the need, and the perception of chemicals in the site.

It is thought that this system may help decrease the antibiotic usage and decrease the treatment cost in farms. The developing effects can be observed with smart delivery systems as well as pharmaceutics, nutraceutics, foods, food supplements, bioactive compounds, probiotics, chemicals, and vaccines carried to the target site. Thus, in the future, by way of nanotechnological improvements, the development of precise delivery systems, sensing self-regulation capability, monitoring large and small animal health, the development of treatment and control processes will be possible with nano-materials for biological and bioactive organisms using perfectly in the target site [7].

\subsection{Nanotechnology in the Diagnosis of Diseases}

In veterinary medicine, the disease of an animal cannot be understood until clinical signs are observed. Infection can be substantially spread in the herd until disease is diagnosed. Nanotechnology displays activity at the same size like virus and disease (infected particle), thus has specific potential for early diagnosis and treatment. Nanotechnology may be effective method in critical clinical diagnoses because of this property [8].

\subsection{Nanotechnology in Vaccine Development}

Vaccine comprises adjuvant and antigen, and stimulates long lasting and protective antibody response. Traditional vaccines strategy from the use of live and dead organisms is shifted to safe synthetic and recombinant vaccines. These new vaccines generally are sensitive to degradation and weak immunogenic, and require optimized adjuvant with augmented immunogenicity [9]. Conventional adjuvants cannot be regulated, but with the development of nanotechnology, a number of new antigen delivery strategies are developed. Application route and decreased dose can be applied to stimulate immune response specific to target (intra nasal 
application is more suitable way to induce immune system of target mucosal system) via these nanoparticle derived adjuvants. By means of this property, it can be used in the event of non-application at the same time or vaccination with traditional methods is inconvenient in species that animal numbers excess [6].

Nanoparticle adjuvants increase immunity of a vaccine by imitating molecular models relating pathogen, providing the regulation of co-stimulatory molecules on antigen-presenting cells, maintenance of immune system and long time delivery of antigens. Nanoparticles can be designed to produce virus like particles that have morphology similar virus capsid and create immune responses not to cause infection [3, 9].

\subsection{Nanotechnology in the Treatment of Diseases}

Veterinary healthy services are a subject on the agenda with increasing source of concern of animal owners and countries. When the high costs of drugs and veterinary healthy services and increase in animal population are considered, innovative solutions are immediately required. The non-effective delivery of therapeutic molecules is high obstacle in obtaining targeted results against disease agents. Many drugs are effective in the treatment of diseases but most of these have specific disadvantages such as toxicity, poor water solubility, and cellular impermeability. In the studies of nanomedicine, it is focused on the therapeutic and diagnostic substances in the forefront, rational delivery of substance in animals, and direction of drugs to specific targets. Area of nanotechnology application that is the most promising and productive in the animal treatment is nanopharmaceutics (Table 1). When small sized and high moving nanoparticles are compared to microparticles, they can be used in the range of extensive biological target because they are taken into cells at the high rate. Nanomaterials such as polymeric nanoparticles, carbon nanotubes, liposomes, dendrimers, nanoshells, nanopores, magnetic nanoparticles are used in the treatment of diseased animals. Design with help of nanomaterials to provide that various new devices and technologies direct the therapeutic substances to the correct site and maintain the pharmacologic activity for sufficient time is the real challenge [10].

\subsection{Nanotechnology in the Improvement of Fertility Functions of Animals}

Nanotechnology is started to be used newly in the subjects of fertility and reproduction in animals. The target of nanotechnology based studies that performed about fertility of animals via this method is to describe their properties at nanoscale of gametes by atomic force microscopy [11]. The purpose of all the innovative studies is to be able to define the subject at nanoscale, solve the fertility problems of animals, and develop products that have not any harm to economy, society and environment $[10,12]$.

2.6 Importance of Biosensors in the Detection of Fertility Capabilities of Animals

Nanobiosensors are highly precise devices equipped with motionless probe biomolecules. Nanobiosensors consist of nanoparticles, nanotubes, nanocables, and nanofibres. The main use area is clinical diagnosis and imaging. The use of nanobiosensors related to reproduction in herd management has a promising future in the correction of detection of diseases, pathogens, estrus cycle, hormone levels, and metabolites [10].

\subsection{Preservation of Gametes and Embryos via Freezing}

Preservation of gonadal tissues, sperms, oocytes, and embryos via freezing facilitated the occurrence of new and exciting study areas about reproduction in animals. Preservation of cells and tissues via freezing with the use of biocompatible metal nanoparticles may provide fast freezing, and rapidly and homogeneously rewarming of the biological materials under 
physiological conditions. In addition, there are many studies about preservation of cells and tissues with the use of nanoparticles $[7,10]$.

\subsection{Nanotechnology in Animal Breeding}

Management of breeding is expensive and time-consuming problem in herds that carried out production of milk. For the purpose of being solution to this concern, to provide the real time measurement of the changes in the blood estradiol level, the studies are being carried out on a nanotube subcutaneously introduced. Nanotubes are used in the follow-up of estrous cycle in animals because these tubes have properties to bind and detect the estradiol antibody during estrous by infrared fluorescence. Signal obtained from sensor would be used for central monitoring when the animal is in estrus. Microfluidics is currently used to significantly simplify the fertilisation procedures carried out under laboratory conditions for the purpose of animal breeding. It is used in animal husbandry to physically classify sperm and eggs. Microfluidics and nanofluidic are the systems analyzed by controlling the flow of fluid and gases via a number of channels and valves [13].

\subsection{Nanotechnology in Farm Products}

Nanotechnology is thought to be effective in the production and development of new products for the purpose of increasing yield of products, extending shelf life, preventing freshness, and increasing the food safety and quality. It is also thought that egg and meat producing times will be decreased. Thus, consumers will obtain egg and meat in a short time. Benefits of fermented farm products on healthy have been confirmed. These products can be obtained in an easy way and in a shortest time via nanotechnology [10].

\subsection{Nanotechnology in Meat Production}

Applications of nanomaterial are generally used for meat and foods nowadays. Nanoparticles and nanomaterials are used as the food constituents or food additives directly introduced into food, or as a part of the materials used for food packet. Micro-encapsulation process can increase dispersing ability of additives dissolved in the fat, improve taste of foods, and decrease the use of fat, salt, sugar, and additives. In the meat industry, decrease of the salt use is important but it is difficult. Although salt use has advantages, its disadvantages are negative effects due to hypertension in the human body. Nano-carrier systems used during the meat process prevent the degradation of food and additives but it increases the occurrence of cardiovascular diseases in an advanced stage of hypertension. Carriers can provide food substances to be resistant to proteases and other denaturing compounds, and prevention of their stabilities to $\mathrm{pH}$ and temperature changes. Nanotechnology can also be used during the process, storage and distribution of micro-nutrients to increase their stabilities [10-14].

Nanotechnology can provide poultry and other meat products cost effective without degradation of their natural features as well as can eliminate differences in the quality of the products via nanotechnology based cooling systems, and rapid and homogenous techniques.

One of the applications of nanotechnology in the future is the changes such as color, flavor, nutrients, differing according to the food taste or its spoilage, (interacted) in the poultry meat. That many of molecular structures determining these properties are in the range of nanometer may have an important role in the production of poultry meat. The purpose is that atoms individually are smartly changed on properties of meat constituents. Thus, the desired taste and structure may be formed by being introduced into the required site of atoms [15].

\subsection{Nanotechnology in Food Safety}

Identity prevention (IP) system is a valuable system by providing information on applications and activities used to produce agricultural product to consumers. Today 
Table 1 Examples related to drugs used in the development stage in veterinary medicine [6].

\begin{tabular}{|c|c|c|c|c|c|}
\hline $\begin{array}{l}\text { Animal } \\
\text { species }\end{array}$ & $\begin{array}{l}\text { Formulation of } \\
\text { nanoparticle }\end{array}$ & Compound used & Purpose of use & $\begin{array}{l}\text { Administration } \\
\text { route }\end{array}$ & Scientific source \\
\hline Cat & Emulsion & Propofol & Anesthesia & Intravenous & Wiese et al. $[16] \bullet \boldsymbol{\nabla}$ \\
\hline Cat & Liposome & Doxorubicin & Soft tissue sarcoma & Intravenous & Kleiter et al. [17] $\bullet \boldsymbol{\square} \boldsymbol{\Delta}$ \\
\hline Cat & Liposome & Interleukin-2 DNA & Chronic rhinitis & Intraperitoneal & Veir et al. $[18] \bullet \boldsymbol{\bullet} \boldsymbol{\Delta}$ \\
\hline Dog & Liposome & Hydromorphone & Analgesia & Subcutaneous & Wunsch et al. [19] $\boldsymbol{\bullet} \boldsymbol{\Delta}$ \\
\hline Dog & Liposome & Clodronate & Malignant histiocytosis & Intravenous & Hafeman et al. [20] $\bullet \boldsymbol{\Delta}$ \\
\hline Dog & Liposome & Trifluralin & Leishmaniosis & Intravenous & Marques et al. [21] $\boldsymbol{\Delta}$ \\
\hline Pig & Polymeric & $\begin{array}{l}\text { E. coli fimbriae } \\
\text { vaccine }\end{array}$ & E. coli & Peros & Vandamme et al. [22] $\boldsymbol{\Delta}$ \\
\hline Pig & Liposome & $\alpha$-tocopherol & $\begin{array}{l}\text { Vitamin } \\
\text { E supplementation }\end{array}$ & Peros & Bontempo et al. [23] $\Delta \Delta$ \\
\hline Pig & $\begin{array}{l}\text { Chromium } \\
\text { nanocomposite }\end{array}$ & Chromium & $\begin{array}{l}\text { Chromium } \\
\text { supplementation }\end{array}$ & Peros & Wang et al. [24] $\boldsymbol{\Delta}$ \\
\hline Cattle & Liposome & Streptomycin & Brucellosis & Intramammary & Nicoletti et al. [25] $\boldsymbol{\Delta}$ \\
\hline Cattle & Niosome & Flurbiprofen & Analgesic & Intravenous & Confalonieri et al. [26] $\triangleleft \Delta$ \\
\hline Cattle & Ring shaped & $\begin{array}{l}\text { Human respiratory } \\
\text { syncytial }\end{array}$ & Bovine respiratory & $\begin{array}{l}\text { Intranasal, } \\
\text { Intramuscular }\end{array}$ & Riffault et al. [27] $\boldsymbol{\Delta}$ \\
\hline Horse & Liposome & 99m-technetium & Imaging & Intravenous & Underwood et al. [28] $\mathbf{~ A ~}$ \\
\hline Horse & Liposome & $\begin{array}{l}\text { Toxoplasma gondii } \\
\text { antigen }\end{array}$ & T. gondiivaccine & Intramuscular & Hiszczynska-Sawicka et al. [29] $\boldsymbol{\Delta}$ \\
\hline Horse & Liposome & Diamidine & Treatment of babesiosis & Intramuscular & Boscan et al. [30] 4 \\
\hline Sheep & $\begin{array}{l}\text { Polystyrene } \\
\text { nano-beads }\end{array}$ & $\begin{array}{l}\text { Foot and Mouth } \\
\text { disease antigens }\end{array}$ & $\begin{array}{l}\text { Foot and Mouth disease } \\
\text { vaccine }\end{array}$ & Intradermal & Greenwood et al. [31] $\boldsymbol{\Delta}$ \\
\hline Sheep & $\begin{array}{l}\text { Polystyrene } \\
\text { nano-beads }\end{array}$ & Ovalbumin & $\begin{array}{l}\text { Assessment of the } \\
\text { nanobeads as an adjuvant }\end{array}$ & $\begin{array}{l}\text { Subcutaneous, } \\
\text { Intramuscular, } \\
\text { Intradermal }\end{array}$ & Scheerlinck et al. [32] $\boldsymbol{\nabla} \boldsymbol{\Delta}$ \\
\hline Bird & $\begin{array}{l}\text { Chitosan } \\
\text { nanoparticle }\end{array}$ & Copper & Copper supplementation & Peros & Wang et al. [33] $\boldsymbol{\Delta}$ \\
\hline Bird & $\begin{array}{l}\text { Polymer } \\
\text { nanoparticle }\end{array}$ & $\begin{array}{l}\text { Chlamydophila } \\
\text { psittacivaccine }\end{array}$ & C. psittacivaccine & Nebulised & Verminnen et al. [34] $\bullet \boldsymbol{\Delta}$ \\
\hline Bird & Liposome & Butorphanol & Arthritis in conures & Subcutaneous & Paul-Murphy et al. [35] $\boldsymbol{\Delta}$ \\
\hline Bird & $\begin{array}{l}\text { DNA chitosan } \\
\text { nanospheres }\end{array}$ & $\begin{array}{l}\text { Newcastle disease } \\
\text { vaccine and } \\
\text { interleukin } 2 \text { gene }\end{array}$ & Newcastle disease vaccin & Intramuscular & Zhang et al. [36] $\bullet \boldsymbol{\Delta}$ \\
\hline
\end{tabular}

- Those used to diseased animals in clinical practices; 4 in pharmacokinetics studies; $\mathbf{c}$ compared with formulations not to include nanoparticle; beneficial effects of formulations comprising nanoparticle; $\boldsymbol{\Delta}$ nanoparticle formulations that not have beneficial effects; $\boldsymbol{\nabla}$ adverse effects.

via IP system, it is possible to access the records on the farm origin, the environmental applications used for production, food safety, animal welfare and the protocols of supplier for giving information to consumers and stakeholders. Quality assurance in the safety of agricultural and animal originated products can be significantly enhanced via IP at nanoscale [13].

\subsection{Nanotechnology in Neutering of Animals}

Although there are advantages related to the use of nanoparticles to improve the reproduction system in animals, some nanoparticles (metal nanoparticles) may have poisoning effects in the body. However, it can be benefited from the poisoning effects of them for the prevention of pregnancy. Many metals including cadmium at low and moderate concentrations depending on their dosages may cause infertility. Systemic poisoning can be prevented by targeting the specific molecules (antibodies) to the reproduction and related organs (pituitary gland) or by using some physical features (magnetic nanoparticles being carried by magnetic field). It is required that scientists make further researches on nanoparticles used for the neutralization of reproductive organs $[10,37]$. 


\section{References}

[1] Benli, B. 2009. "Nanoteknoloji ve antik çağlara uzanan killi nanoyapilar." Journal of Clay Science and Technology 3: 143-62.

[2] Shukla, A., and Tewari, S. N. 2018. "A Brief Review of Nanotechnology.” JoNSNEA 8: 5-8.

[3] Mohantya, N. N., Palaib, T. K., Prustyc, B. R., and Mohapatrad, J. K. 2014. "An Overview of Nanomedicine in Veterinary Science.” Vet Res 2: 90-5.

[4] Goodman, R. P., Schaap, I. A., Tardin, C. F., Erben, C. M., Berry, R. M., Schmidt, C. F., et al. 2005. "Rapid Chiral Assembly of Rigid DNA Building Blocks for Molecular Nanofabrication." Science 310: 1661-5.

[5] Karakaya, S. 2009. "Ürün geliştirmede optimum beslenme yaklaşımı." http://food.ege.edu.tr/files/urun_gelistirmede_optimumbe slenmeyaklasimi.pdf.

[6] Underwood, C., and van Eps, A. W. 2012. "Nanomedicine and Veterinary Science: The Reality and the Practicality." Vet J 193: 12-23.

[7] Tomanek, D., and Enbody, R. J. 2000. Revue Scientifique Technique International Office of Epizootics. 24 (1): 432.

[8] Jain, K. K. 2005. "Nanotechnology in Clinical Laboratory Diagnostics." Clin Chim Acta 358: 37-54.

[9] Nordly P., Madsen, H. B., Nielsen, H. M., and Foged, C. 2009. "Status and Future Prospects of Lipid-Based Particulate Delivery Systems as Vaccine Adjuvants and Their Combination with Immunostimulators." Expert Opin Drug Deliv 6: 657-72.

[10] Meena, N. S., Sahni, Y. P., Thakur, D., and Singh, R. P. 2018. "Applications of Nanotechnology in Veterinary Therapeutics.” J Entomol Zool Stud 6: 167-75.

[11] Saragusty, J., and Arav, A. 2011. "Current Progress in Oocyte and Embryo Cryopreservation by Slow Freezing and Vitrification." Reproduction 141: 1-19.

[12] Scott, N. R. 2007. "Nanoscience in Veterinary Medicine." Vet Res Commun 31: 139-44.

[13] Patil, S. S., Kore, K. B., and Kumar, P. 2009. "Nanotechnology and Its Applications in Veterinary and Animal Science." Veterinary World 2 (12): 475-7.

[14] Lee, K. T. 2010. "Quality and Safety Aspects of Meat Products as Affected by Various Manipulations of Packaging Materials.” Meat Sci 86: 138-50.

[15] Muktar, Y., Bikila, T., and Keffale, M. 2015. "Application of Nanotechnology for Animal Health and Production Improvement: A Review." World Appl Sci J 33: $1588-96$.

[16] Wiese, A. J., Lerche, P., Cleale, R. M., and Muir, W. W. 2010. "Investigation of Escalating and Large Bolus Doses of a Novel, Nano-droplet, Aqueous 1\% Propofol Formulation in Cats." Vet Anaesth Analg 37: 250-7.
[17] Kleiter, M., Tichy, A., Willmann, M., Pagitz, M., and Wollfesberger, B. 2010. "Concomitant Liposomal Doxorubicin and Daily Palliative Radiotherapy in Advanced Feline Soft Tissue Sarcomas." Vet Radiol Ultrasound 51: 349-55.

[18] Veir, J. K., Lappin, M. R., and Dow, S. W. 2006. "Evaluation of a Novel Immunotherapy for Treatment of Chronic Rhinitis in Cats." J Feline Med Surg 8: 400-11.

[19] Wunsch, L. A., Schmidt, B. K., Krugner-Higby, L. A., and Smith, L. J. 2009. "A Comparison of the Effects of Hydromorphone $\mathrm{HCl}$ and a Novel Extended Release Hydromorphone on Arterial Blood Gas Values in Conscious Healthy Dogs." Res Vet Sci 88: 154-8.

[20] Hafeman, S., London, C., Elmslie, R., and Dow, S. 2009. "Evaluation of Liposomal Clodronate for Treatment of Malignant Histiocytosis in Dogs." Cancer Immunol Immunother 59: 441-52.

[21] Marques, C., Carvalheiro, M., Pereira, M. A., Jorge, J., Cruz, M. E., and Santos-Gomes, G. M. 2008. "Efficacy of the Liposome Trifluralin in the Treatment of Experimental Canine Leishmaniosis." Vet J 178: 133-7.

[22] Vandemme, K., Vesna, M., Eric, C., Paul, R. J., and Chris, V. 2011. "Adjuvant Effect of Gantrez ${ }^{\circledR} A N$ Nanoparticles during Oral Vaccination of Piglets against F4+Enterotoxigenic Escherichia coli." Vet Immunol Immunopathol 139: 148-55.

[23] Bontempo, V., Baldi, A., Cheli, F., Fantuz, F., Politis, I., Carli, S., et al. 2000. "Kinetic Behavior of Three Preparations of Alpha-Tocopherol after Oral Administration to Postpubertal Heifers." Am J Vet Res 61: 589-93.

[24] Wang, M. Q., Xu, Z. R., Li, W. F., and Jiang, Z. G. 2009. "Effect of Chromium Nanocomposite Supplementation on Growth Hormone Pulsatile Secretion and mRNA Expression in Finishing Pigs." J Anim Physiol Anim Nutr 93: 520-5.

[25] Nicoletti, P., Lenk, R. P., Popescu, M. C., and Swenson, C. E. 1989. "Efficacy of Various Treatment Regimens, Using Liposomal Streptomycin in Cows with Brucellosis." Am J Vet Res 50: 1004-7.

[26] Confalonieri, E. O., Soraci, A. L., Becaluba, M., Denzoin, L., Rodriguez, E., Riccio, B., et al. 2010. "The Disposition of Free and Niosomally Encapsulated Rac-flurbiprofen in Dairy Bovines." J Vet Pharmacol Ther 33: 9-14.

[27] Riffault, S., Meyer, G., Deplanche, M., Dubuquoy, C., Durand, G., Soulestin, M., et al. 2010. "A New Subunit Vaccine Based on Nucleoprotein Nanoparticles Confers Partial Clinical and Virological Protection in Calves against Bovine Respiratory Syncytial Virus." Vaccine 28: 3722-34.

[28] Underwood, C., Van Eps, A. W., Ross, M. W., Laverman, 
P., van Bloois, L., Storm, G., et al. 2012. "Intravenous Technetium-99m Labeled PEG-Liposomes in Horses: A Safety and Biodistribution Study." Equine Vet J 44: 196-202.

[29] Hiszczynska-Sawicka, E., Oledzka, G., Holec-Gasior, L., Li, H., Xu, J. B., Sedcole, R., et al. 2011. "Evaluation of Immune Responses in Sheep Induced by DNA Immunization with Genes Encoding GRA1, GRA4, GRA6 and GRA7 Antigens of Toxoplasma gondii." Vet Parasitol 177: 281-9.

[30] Boscan, P., Rezende, M. L., Grimsrud, K., Stanley, S. D., Mama, K. R., and Steffey, E. P. 2010. "Pharmacokinetic Profile in Rilation to Anaesthesia Characteristics after a 5\% Micellar Microemulsion of Propofol in the Horse." $\mathrm{Br} \mathrm{J}$ Anaesth 104: 330-7.

[31] Greenwood, D. L., Dynon, K., Kalkanidis, M., Xiang, S., Plebanski, M., and Scheerlinck, J. P. 2008. "Vaccination against Foot-and-Mouth Disease Virus Using Peptides Conjugated to Nano-beads." Vaccine 26: 2706-13.

[32] Scheerlinck, J. P., Gloster, S., Gamvrellis, A., Mottram, P. L., and Plebanski, M. 2006. "Systemic Immune Responses in Sheep, Induced by a Novel Nano-bead Adjuvant." Vaccine 24: 1124-31.

[33] Wang, C., Wang, M. Q., Ye, S. S., Tao, W. J., and Du, Y.
J. 2011. "Effects of Copper-Loaded Chitosan Nanoparticles on Growth and Immunity in Broilers." Poult Sci 90: 2223-8.

[34] Verminnen, K., Beeckman, D. S., Sanders, N. N., De Smedt, S., and Vanrompay, D. C. 2010. "Vaccination of Turkeys against Chlamydophila psittaci through Optimised DNA Formulation and Administration." Vaccine 28: 3095-105.

[35] Paul-Murphy, J. R., Krugner-Higby, L. A., Tourdot, R. L., Sladky, K. K., Klauer, J. M., Keuler, N. S., et al. 2009. "Evaluation of Liposome-Encapsulated Butorphanol Tartrate for Alleviation of Experimentally Induced Arthritic Pain in Green-Cheeked Conures (Pyrrhura molinae)." Am J Vet Res 70: 1211-9.

[36] Zhang, W., Yin, Z., Liu, N., Yang, T., Wang, J., Bu, Z., et al. 2010. "DNA-Chitosan Nanoparticles Improve DNA Vaccine-Elicited Immunity against Newcastle Disease Virus through Shuttling Chicken Interleukin-2 Gene.” J Microencapsul 27: 693-702.

[37] Jha, R. K., Jha, P. K., Chaudhury, K., Rana, S. V., and Guha, S. K. 2014. "An Emerging Interface between Life Science and Nanotechnology: Present Status and Prospects of Reproductive Healthcare Aided by Nano-biotechnology." Nano Rev 5: 22762. 